Silvia Hernández Muñoz ${ }^{1}$, Francisco López Alonso ${ }^{1}$, Chema López Juderías ${ }^{2}$, Isabel Muñoz Tomás ${ }^{3}$, José Prieto ${ }^{4}$, Pedro Luis Hernando Sebastián ${ }^{5}$, Rubén Benedicto ${ }^{6}$, Marta Marco Mallent ${ }^{7}$, José Aznar Alegre ${ }^{7}$, Soledad Córdoba Guardado ${ }^{8}$, Sergio Romero ${ }^{8}$, José Joaquín Pérez Gimeno ${ }^{8}$, María Vidagañ Murgi $^{8}$, Silvia Martí Mari ${ }^{4}$, Rocío Garriga Inarejos ${ }^{4}$

${ }^{1}$ Coordinación Diario de las Bellas Artes, Dpto. Expresión Musical, Plástica y Corporal. Área de Dibujo /Facultad de CC. SS. y Humanas. Universidad de Zaragoza. ${ }^{2}$ Director de Diario de Teruel. ${ }^{3}$ Coordinación Diario de las Bellas Artes. Diario de Teruel. ${ }^{4}$ Dpto. E. M. P. y C. Área de Escultura/Facultad de CC. SS. y Humanas Universidad de Zaragoz. ${ }^{5}$ Dpto. Historia del Arte /Facultad de CC. SS. y Humanas. Universidad de Zaragoza. ${ }^{6}$ Dpto. Filosofía y Estética /Facultad de CC. SS. y Humanas. Universidad de Zaragoza. ${ }^{7}$ Dpto. E. M. P. y C. Área de Pintura /Facultad de CC. SS. y Humanas. Universidad de Zaragoza. ${ }^{8}$ Dpto. E. M. P. y C. Área de Dibujo/Facultad de CC. SS. y Humanas. Universidad de Zaragoza.

\title{
Arte y prensa, innovando en el lenguaje de la comunicación.
}

\section{Art and press, innovation in the language of communication.}

TIPO DE TRABAJO:

Comunicación.

PALABRAS CLAVE:

Arte y prensa. Papel y TIC. Innovación e investigación. Universidad + Prensa + Ciudad.

KEY WORDS:

Art and press. Paper and ICT. Innovation and research. University + Press + City.

RESUMEN.

Diario de las Bellas Artes. Diario de Teruel. Es una colaboración entre Diario de Teruel y el Grado en Bellas Artes de la Universidad de Zaragoza. De forma pionera y ya por segundo año consecutivo, se sustituyen las fotografías de todas las noticias del día por ilustraciones realizadas por alumnos y profesores del grado, incorporando además realidad aumentada, animaciones e interactividad en las páginas.

El Diario de las Bellas Artes, busca la innovación en los periódicos en papel mediante las nuevas tecnologías de la creación y multimedia. Incorpora en prensa impresa - de manera pionera-, noticias interactivas, multimedia, de realidad aumentada. A la interactividad de la version en papel se accede mediante internet, desde teléfonos móviles, tablets u ordenadores.

Pueden verse los dos números anteriores de Diario de las Bellas Artes. Diario de Teruel en el siguiente enlace:

http://diariodelasbellasartes.blogspot.es/ 
Silvia Hernández Muñoz, Francisco López Alonso, Chema López Juderías, Isabel Muñoz Tomás, José Prieto, Pedro Luis Hernando Sebastián, Rubén Benedicto, Marta Marco Mallent, José Aznar Alegre, Soledad Córdoba Guardado, Sergio Romero, José Joaquín Pérez Gimeno, María Vidagañ Murgi, Silvia Martí Marí, Rocío Garriga Inarejos

\section{ABSTRACT.}

"Diario de las Bellas Artes". Diario de Teruel. It is a collaboration between Diario de Teruel and the Grado en Bellas Artes of Universidad de Zaragoza. In a pioneer manner -for the second consecutive year- photographs of all the news of the day are replaced by illustrations made by students and teachers of the degree, incorporating enhanced reality, animations and interactivity inside the pages.

"Diario de las Bellas Artes" seeks innovation in traditional newspapers, through new technologies and multimedia. In agroundbreaking way, it incorporates interactive, multimedia and augmented reality news in written press. You can get access to the interactivity of the paper issue by using internet from your smartphone, tablet or computer.

The two previous editions of "Diario de las Bellas Artes". Diario de Teruel are available in the following link:

http://diariodelasbellasartes.blogspot.es

\section{CONTENIDO}

\section{INTRODUCCIÓN.}

\section{Contexto académico.}

El proyecto se desarrolla en el contexto académico del Grado en Bellas Artes de la Universidad de Zaragoza. Se trata de una actividad transversal e interdisciplinar. Aunque hay asignaturas que por su perfil tienen un grado de implicación mayor: diseño gráfico, ilustración y grabado, permite la actuación de otras disciplinas como pintura, escultura, performance, audiovisuales, animación, etc.

\section{Objetivos.}

- Empresa + Universidad + Ciudad

- Convivencia entre periódico en papel y TIC.

- Trabajo en equipo. Entre los dos números [26/03/2015] y [21/04/2016] han colaborado 110 personas: Más de 15 profesores, 75 alumnos y más de 22 profesionales.

- Visibilidad del Grado en Bellas Artes, sus disciplinas y capacidades, mediante una práctica real. Contacto con el mundo laboral y experiencia para el alumno. Actuar como soporte para la integración de los conocimientos adquiridos en las distintas materias.

- Consolidar el proyecto dentro del ámbito universitario mediante proyectos de innovación docente, transferencia de la investigación y publicaciones científicas, para lograr el reconocimiento del equipo de trabajo y que sirva de currículum al mismo tiempo.

- Reconocimiento como pioneros del proyecto a través de publicaciones científicas.

\section{Necesidad a que responde el proyecto.}

- Difusión y visibilidad del grado en Bellas Artes. Sus disciplinas y posibilidades.

- Relacionar el Grado en Bellas Artes y la Universidad con la Ciudad.

- Práctica real. Contacto con el ámbito profesional.

- Coordinación entre asignaturas. 
Silvia Hernández Muñoz, Francisco López Alonso, Chema López Juderías, Isabel Muñoz Tomás, José Prieto, Pedro Luis Hernando Sebastián, Rubén Benedicto, Marta Marco Mallent, José Aznar Alegre, Soledad Córdoba Guardado, Sergio Romero, José Joaquín Pérez Gimeno, María Vidagañ Murgi, Silvia Martí Marí, Rocío Garriga Inarejos

\section{Conocimiento que se genera.}

El resultado es una forma diferente de contar las noticias. Un producto nuevo y diferente, donde se cuentan las noticias del día con el valor del arte, con un enfoque diferente. La revisión y el juicio crítico en imágenes de los estudiantes y profesores del Grado en Bellas Artes.

Innovación en prensa por medio de TIC. Generación de manera pionera, de noticias con realidad aumentada e interactividad partiendo del soporte papel.

Transferencia de la investigación a la empresa y al aula. En el proyecto "Investigación en grabado, diseño e ilustración: Nuevos medios. El libro digital" de la Fundación Universitaria "Antonio Gargallo", investigamos y desarrollamos la interconexión entre el soporte papel y los medios digitales, partiendo del soporte libro en papel como punto de partida y generando contenido multimedia mediante apps. En el Diario de las Bellas Artes realizamos una innovación similar pero sobre el periódico Diario de Teruel, en lugar de sobre el soporte libro.

Es una práctica real para los alumnos, y el primer contacto con empresa real, donde se inician en su modo de trabajo, organización y tiempos. Conocen los medios de comunicación, la selección de información, el recorrido de las noticias, contenidos y seguimiento de noticias a lo largo del tiempo. Trabajan con los plazos y tiempos de un periódico y desarrollan un trabajo completo en el día.

\section{METODOLOGÍA DOCENTE UTILIZADA.}

El proyecto se enmarca en el contexto de las llamadas Metodologías Activas. Partimos de la metodología del tipo Aprendizaje basado en proyectos $(A B P)$, reforzada por una estrategia de autoevaluación de mejora continua. Es significativa también una metodología interactiva, marcada por el trabajo en equipo: la coordinación con la empresa, la comunicación entre alumno - profesional/redactor profesor y, el apoyo, comunicación y colaboración con otros docentes. A modo de gráfico podríamos exponer la metodología docente:

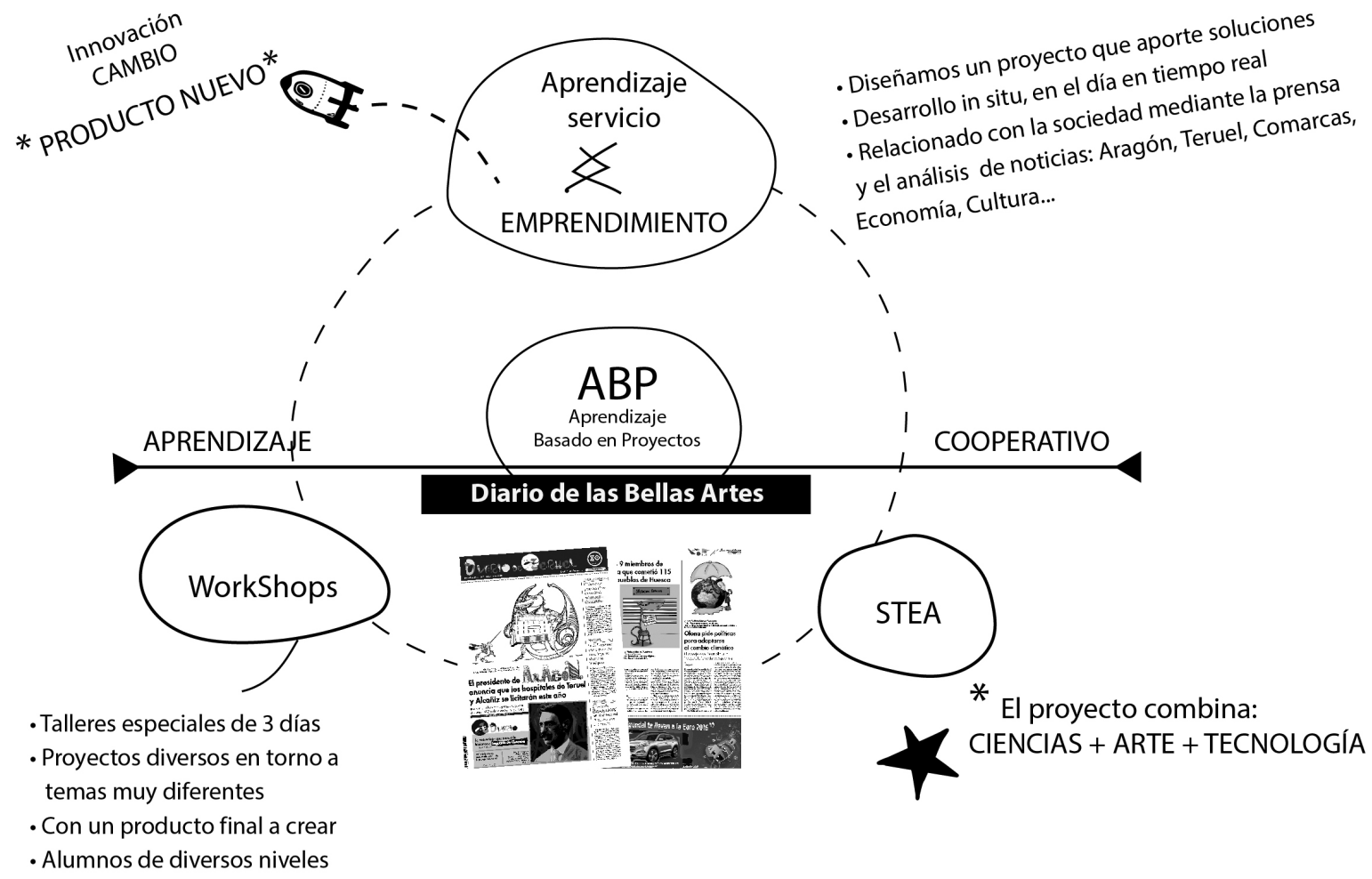

Imagen 1: Representación esquemática de las diversas metodologías activas llevadas a cabo en el proyecto Diario de las Bellas Artes. 
Silvia Hernández Muñoz, Francisco López Alonso, Chema López Juderías, Isabel Muñoz Tomás, José Prieto, Pedro Luis Hernando Sebastián, Rubén Benedicto, Marta Marco Mallent, José Aznar Alegre, Soledad Córdoba Guardado, Sergio Romero, José Joaquín Pérez Gimeno, María Vidagañ Murgi, Silvia Martí Marí, Rocío Garriga Inarejos

Arte y prensa, innovando en el lenguaje de la comunicación.

III CONGRESO INTERNACIONAL DE INVESTIGACIÓN EN ARTES VISUALES :: ANIAV 2017 :: GLOCAL [codificar, mediar, transformar, vivir] http://dx.doi.org/10.4995/ANIAV.2017.5712

El diseño de este ABP con Diario de las Bellas Artes constituye un proyecto integrador donde los conocimientos adquiridos en las clases tienen que dar lugar a un producto final real, innovador y diferente, cuya base está en la teoría de John Dewey "Learning by doing": El mejor aprendizaje es el experiencial: aprender haciendo. Si analizamos las diversas metodologías que hemos empleado:

a) Innovación: El resultado es un producto nuevo, una forma diferente de contar las noticias a través del arte donde además se integra papel y TIC. Influyen componentes de innovación, de investigación y cambio.

b) Aprendizaje servicio y Emprendimiento: Hay factores que relacionan el trabajo con la comunicación con la sociedad, está conectado con la realidad y aborda las noticias con carácter activo y reflexivo. También está vertebrado por una idea de emprendimiento y de novedad como agente de cambio.

c) STEA: El proyecto combina Ciencias + Arte + Tecnología. Los alumnos desarrollan el proyecto que da solución a un problema real, complejo, significativo e interesante, y que combina conocimientos de varias disciplinas: ilustración, infografía, diseño gráfico, audiovisuales, animación 2D y 3D, análisis de la imagen e historia del arte... Ello conlleva además un análisis de los medios de comunicación y noticias de actualidad, con puestas en común y debate en las clases sobre cómo expresar gráficamente la información y la evolución de las noticias.

d) Aprendizaje cooperativo: los alumnos trabajan en equipo para conseguir el resultado final: analizan las noticias, realizan propuestas y bocetos y finalmente se decantan por una solución. En el proyecto es clave la INTERDISCIPLINARIEDAD, ya que muchas competencias de las que se desarrollan en la práctica provienen de diversas asignaturas. También les permite trabajar de manera trasversal entre varias asignaturas, iniciar el trabajo con una técnica pictórica, por ejemplo y terminarlo con ilustración digital o incorporando interactividad o animación.

e) Workshops: En la práctica en el día sobre ilustración de noticias, el aprendizaje es autodirigido en un escenario real: los alumnos, de manera competente, saben y saben qué hacer con lo que saben. Para ello, hemos realizado previamente diversos Workshops, o talleres de tres días sobre: "Taller de análisis de medios, noticias y su representación en imágenes". "Taller de creación de conceptos" y "Taller de técnicas rápidas de ilustración y recursos gráficos", donde conjugamos lo mejor de la clase expositiva con prácticas de aprendizaje basado en problemas y talleres.

f) El resultado es un análisis de las noticias visualizando la solución a través del producto final.

\section{Organización de equipos de trabajo:}

Equipo de coordinación empresa + Universidad:

El equipo de coordinación de Diario de Teruel y Grado en Bellas Artes, realizamos una planificación de tiempos y contenidos. Trabajamos propuestas diferentes e innovadoras que le den un carácter diferencial y de calidad al proyecto. Se realizan reuniones periódicas desde comienzo de curso, quincenales y conforme se avanza la fecha de la actividad reforzamos la coordinación con reuniones semanales. Al mismo tiempo, realizamos reuniones con los profesores que coordinarán el trabajo de los alumnos.

Actividades realizadas:

a) Planteamiento del proyecto desde la perspectiva de Innovación Docente y buenas prácticas. Aplicación de metodologías activas como "Aprendizaje basado en proyectos" y otras. Estudio de las posibilidades. Incorporación de la actividad en la programación docente de una o varias asignaturas.

b) Reuniones con el equipo de investigación. Para realizar la transferencia de la investigación al aula. Desarrollo de un proyecto de equipo. Empresa (Diario de Teruel) + Universidad (docentes del proyecto de innovación). Estudio de las posibilidades de interacción del proyecto. Desarrollo informático. Reuniones específicas, puesta en común de resultados durante el proceso.

c) Creación de un cuerpo teórico en torno a la relación arte国prensa. Trabajo de campo: Investigación sobre la innovación en medios digitales en prensa escrita. Recopilación de ejemplos.

d) Estudio de otras posibilidades de empleabilidad del proyecto. 
Silvia Hernández Muñoz, Francisco López Alonso, Chema López Juderías, Isabel Muñoz Tomás, José Prieto, Pedro Luis Hernando Sebastián, Rubén Benedicto, Marta Marco Mallent, José Aznar Alegre, Soledad Córdoba Guardado, Sergio Romero, José Joaquín Pérez Gimeno, María Vidagañ Murgi, Silvia Martí Marí, Rocío Garriga Inarejos

Arte y prensa, innovando en el lenguaje de la comunicación.

III CONGRESO INTERNACIONAL DE INVESTIGACIÓN EN ARTES VISUALES :: ANIAV 2017 :: GLOCAL [codificar, mediar, transformar, vivir] http://dx.doi.org/10.4995/ANIAV.2017.5712

Equipos de trabajo con alumnos:

a) Ilustración de las noticias del día. Aprendizaje in situ y en tiempo real. Los alumnos acuden a la sede de Diario de Teruel a primera hora de la mañana y tienen que aportar una solución antes del cierre del periódico. Se aplica la metodología de Aprendizaje colaborativo, creando equipos de alumnos compensados atendiendo a sus capacidades. Se ponen en práctica conocimientos adquiridos en disciplinas como Diseño Gráfico, llustración y Animación.

ACTIVIDADES REALIZADAS. Reunión en el diario con el equipo de redacción a primera hora, donde se realiza la asignación de noticias a los alumnos que las van a ilustrar. Acudir a ruedas de prensa en el día. Análisis y reflexión con los profesores y con el equipo de Diario de Teruel sobre el modo de abordar la noticia, qué enfoque es más significativo y cómo comunicarlo en imágenes. Diseño e ilustración de la noticias mediante técnicas manuales y/o digitales. Los alumnos trabajan en la sede del diario o en el aula tutorizados por un profesor.

- Creación artística y documentación digital. Creación de las propias ilustraciones del diario de las Bellas Artes por parte de los alumnos, después de diversas sesiones y talleres en el aula. Los alumnos pueden desarrollar una imagen que ilustrará la noticia en papel o además añadirle movimiento en formato GIF, galerías fotográficas, animaciones, abrir enlaces y ver imágenes en 3D.

Ilustración de reportajes atemporales. En este ejemplar del periódico se busca el énfasis en los temas culturales y por ello, se aportan dichos artículos en profundidad, que requieren una mayor elaboración en las ilustraciones y textos.

b) Permite transversalidad con otras asignaturas como pintura, escultura, audiovisuales... que requieren de mayor tiempo de ejecución. Permite también un mayor desarrollo de las TIC. Se trata de noticias que podemos tener previstas, sobre todo de temas culturales, o de noticias de actualidad que tienen un recorrido a lo largo de los días. Aún así, cabe destacar la destreza del alumnado para la resolución rápida de algunas propuestas (por ejemplo retratos de personajes).

\section{ACTIVIDADES REALIZADAS:}

I. Creación de realidad aumentada en las noticias. A partir de las imágenes e ilustraciones de las noticias en versión papel, se accede a contenidos digitales a través de la aplicación Play Store, donde se descargan, de manera gratuita de contenidos que amplían la información. Los contenidos pueden desarrollarse mediante imágenes de realidad aumentada, 3D en movimiento, animación, audiovisuales y otros.

II. Ilustración de las noticias mediante técnicas cuyo proceso de realización requiere de mayor tiempo: escultura, pintura, audiovisuales.

c) Generación de contenidos. Los alumnos y profesores proponen contenidos a incluir en el Diario de las Bellas Artes. Esta edición, aunque recoge las noticias de actualidad tiene también un eminente enfoque cultural. Se incluyen textos de investigación de los profesores y grupos de investigación y exposiciones realizadas por alumnos.
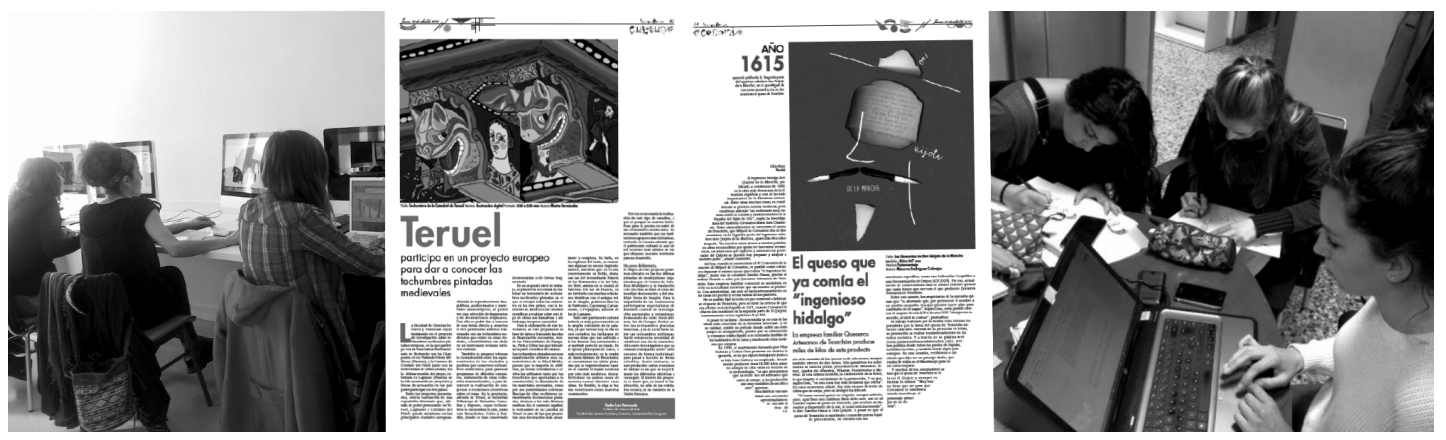

Imagen 2: Alumnos de 3. y 4. curso del Grado en Bellas Artes trabajando en la edición del Diario de las Bellas Artes. Las fotografías están tomadas durante la sesión de trabajo del 25/04/2016 en el Aula de Diseño Gráfico del Edificio de Bellas Artes (izda.) y en la sede de Diario de Teruel (dcha.). En el centro se muestran algunas páginas de Diario de las Bellas Artes. 
Silvia Hernández Muñoz, Francisco López Alonso, Chema López Juderías, Isabel Muñoz Tomás, José Prieto, Pedro Luis Hernando Sebastián, Rubén Benedicto, Marta Marco Mallent, José Aznar Alegre, Soledad Córdoba Guardado, Sergio Romero, José Joaquín Pérez Gimeno, María Vidagañ Murgi, Silvia Martí Marí, Rocío Garriga Inarejos

Arte y prensa, innovando en el lenguaje de la comunicación.

III CONGRESO INTERNACIONAL DE INVESTIGACIÓN EN ARTES VISUALES :: ANIAV 2017 :: GLOCAL [codificar, mediar, transformar, vivir] http://dx.doi.org/10.4995/ANIAV.2017.5712

\section{TIC UTILIZADAS.}

\section{Medios de información y comunicación:}

Prensa en papel y digital. Revisión de las noticias y seguimiento en otros medios: televisión, radio, Facebook, Twitter. Puesta en común en el aula sobre la actualidad internacional, nacional y local. Análisis de las imágenes de prensa y de las noticias ilustradas e infografías, puesta en común y análisis del lenguaje visual para contar mensajes.

\section{Software utilizado:}

Realidad aumentada: Vuforia y Unity. Códigos Bidi. Animaciones: Adobe Photoshop y Adobe Flash. Programas de tratamiento de imágenes e ilustración: Adobe Photoshop y Adobe Illustrator. Generación de imágenes con código: Processing. Programas de diseño y maquetación: Adobe InDesign/QuarkXPress. Grabación y edición de video y audio: IMovie, Adobe Premiere. Difusión: Youtube.

Se crean dos tipos de acceso a la información digital. Mediante código QR con enlace directo a la animación en youtube y mediante Imagen-código con enlace a PlayStore donde se descarga el contenido audiovisual mediante una app.
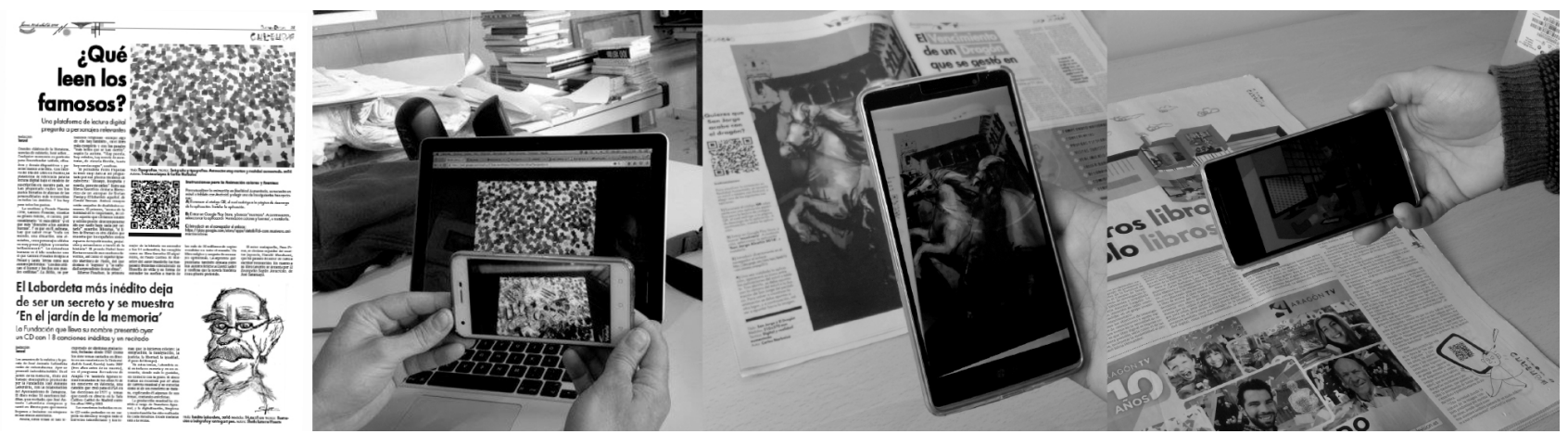

Imagen 3: Algunos ejemplos de acceso en interactividad del periódico con contenidos digitales. (Dcha.) Página de Diario de las Bellas Artes con interactividad mediante código QR impreso y mediante imagen-código. (Izda.)

\section{CARÁCTER INNOVADOR.}

De manera pionera colaboran un periódico, Diario de Teruel, y una universidad, la Universidad de Zaragoza, para contar las noticias del día de un modo diferente: no se trata de un número especial, sino de ilustrar íntegramente las noticias, con el rigor de la información, la inmediatez de los medios de comunicación, pero también con la reflexión en imágenes de los alumnos del Grado en Bellas Artes. Así las habituales fotografías de prensa se sustituyen por imágenes e ilustraciones de los alumnos y profesores del Grado en Bellas Artes.

El diario en papel se vincula con las nuevas tecnologías. A través de sus páginas, las imágenes muestran interactividad mediante realidad aumentada, animaciones, etc. que se desarrollan a través de códigos Bidi o imágenes-código mediante apps.

Desde el punto de vista de la innovación docente supone un proyecto de ABP híbrido entre disciplinas de la titulación, con la transferencia de aspectos tecnológicos de investigación al aula y a la empresa, y la práctica real. 
Silvia Hernández Muñoz, Francisco López Alonso, Chema López Juderías, Isabel Muñoz Tomás, José Prieto, Pedro Luis Hernando Sebastián, Rubén Benedicto, Marta Marco Mallent, José Aznar Alegre, Soledad Córdoba Guardado, Sergio Romero, José Joaquín Pérez Gimeno, María Vidagañ Murgi, Silvia Martí Marí, Rocío Garriga Inarejos

\section{INDICADORES SOBRE LAS MEJORAS OBTENIDAS EN EL PROCESO DE APRENDIZAJE.}

- Mejoras obtenidas en el aprendizaje de los alumnos:

- La clave para potenciar el aprendizaje: el desarrollo de un proyecto real.

- Motivación: currículum, reconocimiento social y en su entorno.

- El punto que consideramos más importante: satisfacción personal por el trabajo bien realizado.

- Mejoras obtenidas en la docencia:

- Actualización de contenidos en las asignaturas.

- Transvase de la investigación al aula.

- Incorporación del "caso real" a la práctica docente.

- Coordinación entre asignaturas de manera horizontal y transversal.

- Oportunidad de trabajar en equipo con la motivación de un proyecto de impacto.

Para obtener los indicadores de éxito expuestos anteriormente hemos aplicado una metodología de evaluación interna, realizada por los mismos integrantes del proyecto, y en la que hemos analizado los siguientes parámetros:

- El aula, relación entre el proyecto, procesos de aprendizaje y competencias. El proceso del proyecto, los resultados y el impacto.

- La oportunidad de incorporación de TIC en el proyecto, mediante la trasferencia de la investigación al aula. Los aspectos sociales en cuanto a la repercusión en la ciudad del proyecto, la respuesta de la gente y la motivación del alumnado. Los medios, infraestructura, equipamiento y software necesario para el proyecto. $Y$ los resultados de aprendizaje de los alumnos en el contexto de las asignaturas con mayor implicación.

El procedimiento de evaluación ha consistido en de monitoreo permanente: basado en la autoevaluación y aplicado en el transcurso de la actividad mediante la supervisión y orientación en los ejercicios realizados por los alumnos, y con la experiencia del curso previo.

Hemos realizado también una autoevaluación una vez finalizado el plazo de ejecución, para evaluar los efectos del proyecto a medio y corto plazo. Valoración de Resultados.

\section{SOSTENIBILIDAD Y TRANSFERIBILIDAD.}

Las prácticas individuales y aprendizajes llevados a cabo por los alumnos: ilustraciones, animaciones, realidad aumentada, diseños... son transferibles al ámbito profesional: al sector editorial por extensión y del diseño gráfico, de manera inmediata. Aunque el proyecto en su conjunto: la coordinación, la creación de imágenes en el día con tiempo limitado hasta la hora de cierre del diario y la incorporación de innovación en interactividad en algunas de ellas supone un proyecto de gran implicación.

En la continuidad y sostenibilidad del presente trabajo resulta básica la colaboración de un grupo de profesores, así como la participación del estudiante para que la actividad sea viable.

Actualmente es un proyecto de innovación docente de la Universidad de Zaragoza: PIIDUZ_16_059 “Diario de las Bellas Artes. Periódico en papel y Nuevos medios. Práctica real: comunicación, información y tecnología". Y hemos previsto una estrategia para consolidar el proyecto, y mantener el registro y reconocimiento como pioneros a nivel mundial mediante comunicaciones en 
Silvia Hernández Muñoz, Francisco López Alonso, Chema López Juderías, Isabel Muñoz Tomás, José Prieto, Pedro Luis Hernando Sebastián, Rubén Benedicto, Marta Marco Mallent, José Aznar Alegre, Soledad Córdoba Guardado, Sergio Romero, José Joaquín Pérez Gimeno, María Vidagañ Murgi, Silvia Martí Marí, Rocío Garriga Inarejos http://dx.doi.org/10.4995/ANIAV.2017.5712

congresos y publicaciones en revistas de investigación a nivel nacional e internacional. Presentamos esta comunicación en la VII Jornada de Buenas Prácticas en la Docencia Universitaria con apoyo de TIC de la Cátedra Banco Santander y Universidad de Zaragoza. Hemos registrado Diario de las Bellas Artes I y II en el Registro de la Propiedad Intelectual del Gobierno de Aragón. También mantenemos el blog citado al inicio de este texto con toda la información y enlaces al respecto. $Y$ tenemos previsto realizar publicaciones en revistas especializadas. El proyecto tiene carácter de continuidad pues estamos preparando su tercera edición.

\section{CONCLUSIONES.}

- El proyecto ha resultado una mejora cualitativa en el aprendizaje, además de una práctica de motivación.

- Diario de las Bellas Artes. Diario de Teruel, ha servido para mejorar la empleabilidad del alumnado en Bellas Artes.

- El proyecto tiene carácter de continuidad, potenciando estrategias de calidad, creatividad e innovación para obtener un resultados futuros diferenciales.

- El tiempo invertido en la docencia se puede justificar como constitutivo de currículum vítae. Así, hemos planteado una estrategia para dar visibilidad al proyecto, reconocimiento y registro como pioneros a nivel mundial: proyecto de innovación docente, página web, publicaciones, referencias en revistas especializadas y de difusión, comunicaciones en congresos, participación en premios y otros.

- En el ámbito periodístico y de la comunicación ha supuesto la práctica de una forma diferente de contar las noticias.

- La tirada del Diario de las Bellas Artes. Diario de Teruel, triplica en número de ejemplares y en número de páginas la tirada y el formato habitual del periódico. La repercusión del proyecto y la respuesta de la ciudad ha superado ampliamente los objetivos previstos, como puede verse en la selección:

\section{Repercusión en los medios.}

- 20 minutos http://www.20minutos.es/noticia/2415376/0/diario-teruel-publica-numero-extraordinario-ilustrado-por-alumnosdocentes-bellas-artes/

- ABC http://agencias.abc.es/agencias/noticia.asp?noticia=1825925

- La 2 Noticias https://www.youtube.com/watch?v=70080EdnoO0

- TVE Aragón https://www.youtube.com/watch?v=6yvV6WbGNws

- Aragón Radio http://www.aragonradio.es/podcast/emision/el-diario-de-teruel-\%E2\%80\%98cede-sus-paginas-a-los-estudiantes-debellas-artes/

- Aragón Radio 2015 http://www.aragonradio.com/diario-de-teruel-publica-un-numero-extraordinario-ilustrado-por-alumnos-ydocentes-de-bellas-artes/

- Aragón Digital http://www.aragondigital.es/noticia.asp?notid=143960

- El Periódico de Aragón http://www.elperiodicodearagon.com/noticias/aragon/venden-ilustraciones-diario-bellas-artes-bancoalimentos_1108193.html

- Blog La buena prensa http://labuenaprensa.blogspot.com.es/2015_03_01_archive.html

- http://labuenaprensa.blogspot.com.es/2016/04/excelente-repeticion.html 
Silvia Hernández Muñoz, Francisco López Alonso, Chema López Juderías, Isabel Muñoz Tomás, José Prieto, Pedro Luis Hernando Sebastián, Rubén Benedicto, Marta Marco Mallent, José Aznar Alegre, Soledad Córdoba Guardado, Sergio Romero, José Joaquín Pérez Gimeno, María Vidagañ Murgi, Silvia Martí Marí, Rocío Garriga Inarejos

Arte y prensa, innovando en el lenguaje de la comunicación.

III CONGRESO INTERNACIONAL DE INVESTIGACIÓN EN ARTES VISUALES :: ANIAV 2017 :: GLOCAL [codificar, mediar, transformar, vivir] http://dx.doi.org/10.4995/ANIAV.2017.5712

\section{FUENTES REFERENCIALES.}

Bazarra, L. Y Casanova, O. La escuela ya no es un lugar. La revolución metodológica está creando futuro, Madrid: Arcix Formación, 2016.

Blacker, H., 'Learning from experience' in (eds.) L. Deer Richardson and M. Wolfe, Principles and Practice of Informal Education, London: Routledge Falmer, 2001.

Cairo, A. El arte funcional: infografía y visualización de información. 1.a ed. Madrid: Alamut, 2011.

Jullier, L., La imagen digital. De la tecnología a la estética. La Marca, 2004.

Manovich, L., El lenguaje de los nuevos medios de comunicación. La imagen en la era digital. Paidós, Barcelona, 2005.

Ord, J., John Dewey and Experiential Learning: Developing the theory of youth work, Youth \& Policy, 2012,

http://www.youthandpolicy.org/wp-content/uploads/2013/07/ord-yandp108.pdf

Prado, E., "El lenguaje multimedia. Una nueva forma de comunicación”, en Actas del Congreso Comunicar no século XXI. Universidad de Santiago de Compostela.

Rheingold, H., Multitudes inteligentes. La próxima revolución social. Gedisa, Barcelona, 2005.

Scolari, C., Hacer clic. Hacia una sociosemiótica de las interacciones digitales. Gedisa, Barcelona, 2000. 